\title{
Discovering Oneself and Discovering Ourselves with the Help of Literature: Educational Possibilities of Narrative
}

\author{
Alfredo Rodríguez-Sedano, Aurora Bernal Martínez de Soria, Miguel Rumayor \\ Department of Education, University of Navarra and University of Panamericana, Pamplona, Spain and Guadalajara, México. \\ Email: \{arsedano, abernal\}@unav.es, mrumayor@up.mx \\ Received May $12^{\text {th }}, 2010$; revised June $2^{\text {nd }}, 2010$; accepted June $10^{\text {th }}, 2010$.

\begin{abstract}
Undoubtedly narrative in education has frequently been studied. Nonetheless, in this paper we want to explore the different educational possibilities offered by narrative in order to discover identity through tradition. MacIntyre's thought offers the categories of practice, tradition and narrative, in order to penetrate the central questions of personal identity and communicability that we consider the most suggestive. Some authors understand narrative as a very accurate means to access tradition and self-knowledge as well as to show the unity of human life and to vindicate the unity of tradition that we can face and those elements that constitute our moral habitat.
\end{abstract}

Keywords: Education, Narrative, Identity, Tradition, Moral

\section{Introduction}

We can add to the well-known expression of Gadamer "a comprehensible being is language" [1] another not less famous from Spaeman "the wealth of reality only becomes unveiled through the language that links us to others" [2]. Both judgments introduce the idea of what else we could try from the educational perspective in order to contribute to the solution of some relevant problems. Both theoreticians of education and educatorsthose who apply their energies to practice - think about the following paradoxical and peculiar stages of Postmodernity. People use efficient elements of information; nonetheless, they lose interest and motivation in understanding reality. People have access to communication technology that facilitates establishing contacts over the limits of space, and somehow over time; nonetheless, isolation and anomie are the lived experience of many people. It is paradoxical that our culture praises the value of liberty, creativity and subjectivity, ignoring that the number of problematic subjects, uprooted and lost among novelties, which is proportionally increasing with that idea.

These three situations hold an existential relationship and have repercussions on educational stances. On the one hand, it is easy to prove that people afflicted by these negative conditions can not educate and are hardly educable. It is possible from the educational intervention to help people to a better self-knowledge as well as to help them to know others. In this way they could push forward their interpersonal communication and through it their social life, as well as their interest in reality. The consideration of narrative by educational theorists illustrates the orientation that we should give to educational practice in order to face the goals described above. In this vein, we have to underline the ideas of a thinker, MacIntyre; through his categories of practice, tradition and narrative, we can access central questions of personal identity and communicability [3].

In order to demonstrate all these points we will follow these steps: a) understand tradition as a basic dimension of identity; b) consider narrative as very efficient means of accessing tradition and understanding who we are; c) consider that traditions can only have influence on educational models through agents integrated into them in a very committed way; d) narrativity in education is also necessary in order to show people in an understandable way the unity of human live as well as to vindicate as a society the unity of traditions that we contact, and those elements that constitute our nutritional moral habitat.

\section{Identity and Tradition}

Clearly the question of identity is one of the many aspects that underlie reading and narrative [4-6]. Above all there is one idea of identity behind those aspects that 
supports each different prospective. Frequently we call identity that which the person chooses for herself with hardly any conditional references where others can be included. This notion of identity underlies liberty as an absolute and produces isolation in individuals. Identity can also be thought of as the result of rational construction through the generalization of values. In this matter each individual is what she simply considers her inscriptional group by age, beliefs, economical status, culture, etc. Nonetheless, there is another possible interpretation of identity, that one is related to origin.

We consider that identity has a reference to origin. It is not established as something definitely given, as an unchangeable fatum at the personal life that has as a result a terrible and unavoidable design. Identity as a start means a "departure point". For its essential character of coexistence and openness is the initial step of the personal life and of the flourishing of a culture. On the other hand the "Modern Identity"- - using the expression of Ch. Taylor-implies the consolidation of the close individualism and fatally brings us to solipsism. Both A. MacIntyre and Ch. Taylor, not participating in this correct notion of identity as origin, have considered and censured the effects of Modern Identity in the mentioned way. For Taylor [7] the derived influences of that idea have produced an erosion of the traditional and common links. Ch Taylor demands a reaffirmation of the proper values of ordinary life, especially those directly related to family life and work. This is the necessary path in order to recover and to renew the true human spirit. Taylor [7] also insists on the formational properties of art and literature.

In another light, MacIntyre [8] recognizes tradition as an essential dimension of personal identity that is conceived as something received and developed at the heart of a community, and which sustains the continuity of subjects' life as a "unity of search" [9]. In this conception, tradition is not a dead weight; a heavy burden that we can hardly bear, and that undermines and cuts the wings of any innovation. Tradition is something given and for this reason is a source for the possible changes carried out by subjects within a community, made by responsibility and solidarity. It is not a matter of reviving the dead tradition but of updating dialogue with a living tradition which is "the requirement of a real scientific progress: progress that only occurs in a learning community" [10].

In order to keep speaking about identity it is necessary to become closer to better clarify the meaning of community that which joins me to others and helps me discover who I am and what I am [11].

\section{Narrative as Mean for Accessing into Tradition}

There are numerous thinkers that underline from differ- ent stances the dimension of narrative in human life [12]. Let us highlight some of the main contributions in order to understand their educational relevance. In After Virtue MacIntyre remarks a relevant aspect for self-knowledge; he posits "human action as a narrative in action" [13]. Also in relation to that idea Barbara Hardy wrote "we dream in narrative, we daydream in narrative, remember, anticipate, we hope, despair, believe, doubt, plan, review, criticize, build, learn hate and love by narrative" [14]. Using narrative through told stories supposes a way of practically experiencing human actions [15].

Narrative as non-arbitrary model of knowledge has been exposed, among others, by Mink. According to Mink [16] there are in a general sense three ways of comprehension.

a) The theoretical way (or hypothetical-deductive) that goes from the universal to the particular through which we can learn concrete things by way of example.

b) The categorical way which explains reality through the use of general and abstract notions (categories) extracted from the observation of reality.

c) The configuring way in which the central category is narrative. The configuring way is that which composes a series of objects in a unique complex of relationships.

The tool used for this configuring operation is the "narrative of the plot" (the Aristotelian mythos). Speaking about comprehension, the plot is able to make "a synthesis of the heterogenic", since it allows the union in intelligible unity of different elements, such as the actions with agents, the aims, means, initiatives, the non undesired circumstances, etc [17]. The narrative mode is presented as the best way of describing human action, as the most suitable to describe human action with the components that integrate it, its conceptual network [18] Told stories make reference to a tradition. When narrative is reached by means of those stories we have experience of human action. Exactly what connects tradition with action is narrative.

Narrative is what, in the end, gives us the "who" of the action that is to say, what reveals the identity. In effect, as H. Arendt [19] remembers, whenever we tried to define who man is we are tangled in a series of descriptions that retract the answer because they say to us, in fact, what man is. Man, continues Arendt [20]— see also MacIntyre [13], reveals himself by his actions and speech, but since the speech in action is narrative, the last word on human identity, the understanding of himself and others in relation to oneself, has a narrative form. Indeed, as Den Heder and Fidyk affirm "Hannah Arendt suggested that a life that is "specifically human" shares a story with others" [21]. These considerations introduce the 
category of narrative identity that together with theory of narrative has been applied to educational practice $[22,23]$.

It is not strange that, for many theoreticians, narrative has become a suitable category to describe those human sciences in which the speech and temporality are implied in some form. It is through the help of narrative that we can access understanding of ourselves, that we can give ethical value to actions in the framework of a narrated life [13]. That History [24,25] can be understood with its educational [26] implications, or even, as all critical [27] speech must be understood at the end.

\section{In search of Educational Tradition}

In this context it can be argued that we live in a world characterized by the diversity and rivalry of traditions and some programs even try to do without any tradition. Undoubtedly it is and was always in such a way. This rivalry entails different educational models that compose diverse visions of the educational process and the task of the teacher. And this can provoke a certain disappointment insofar as we are not able to establish the real requirement in a learning community: dialogue [28,29]. This situation transcends the social scope. Traditions can only have influence on educational models through agents who integrate themselves into them in a more or less committed way. This requires that tradition be embodied in all practice.

In this light MacIntyre [13] suggests the convenience of integrating the different practices as a means of reaching a full human development as well as abandoning the perplexity that is trapping us. These practices entail four characteristics.

- Coherency: there must be activities with consistent rational and foundational structures.

- Complexity: enough to give certain enrichment to the participants.

- Sistematicity: that is to say, it is not sufficient to have sporadic activities. Some structure and interdependency must have been reached.

- Cooperation: There must be activities with enough participant cooperation.

Every practice thought in this way entails internal goods that MacIntyre calls models of excellence that suppose an ideal of future. Every practice has proper goods, entails learning and is also rooted in the past. These internal goods have the possibility, within the practice, to manage the conduct of those who are participating in it, being specified in a concrete order and in internal rules.

Thus, what is a luminous signal of a good practice is that those goods, internal and specific to this activity, which are only well understood insofar as they are prac- tical, grow systematically, becoming deeper and more attainable. Increasingly they bond among participants and extend to others as well as to different practices. This is the measure of the good state of a practice. It is not enough to have a practice but it is also necessary to have a moral order, thus for MacIntyre "moral order is the indicative of a good practice (...) the practice would flourish in societies with very different codes, not so in societies where virtues are unvalued. Nonetheless, other practices would flourish in institutions and with technical skills valid for unified purposes" [13]. Practices are related to every type of social collaboration; therefore, they also include the relation of collaboration that is produced in education. It is well known that MacIntyre has been critiqued for his idea when he speaks of teaching as a practice [30].

Why do we insist on this integration of diverse practices? For MacIntyre [8] the integration of diverse practices entails a fruitful collaboration between educators and the educated at the heart of the practice itself, the right place where the distinction can be learnt between the following:

a) The distinction about what is really good and what seems good for the student.

b) The distinction between what is good for me, in my particular learning level, and what is always good.

These practices should be maintained throughout life regardless of the degree of maturity of students at the scope of the practices. But a key element for those practices to be effective in the educational process requires authority. It is a rational teaching authority, and authority worth trusting that comes from a self-rational knowledge [31]. Departing from this authority, we should accept that intellectual and moral habits are necessary to be a good and autonomous educated citizen [8]. Authority that is reflected in the virtues that belong to tradition is represented by the teacher. It is not really recognized by the student till the educator has not internally incorporated them at least in a partial way.

The recognition of authority is especially relevant in two moments of the educational process.

a) When it happens before comprehension. It is through trust in authority that one can be introduced to tradition.

b) In the process of understanding we follow a teacher that helps us to move on to higher degrees of intelligibility, thus "we can never do this in our mortal life without the authorized testimony of someone that consists of leading us further from where we were" [8].

The necessity of authority is fundamental during the learning process. Authority is also a permanent condition as far as learning is necessary during the whole life [32]. 
The importance of educational practices drives us to give value to tradition and authority. In doing so, the educational value of community takes a relevant dimension as a political scope that could bring a tradition, with enough extension to place the different practices in a concrete human group. MacIntyre is speaking about different social habits, where not only intrinsic criteria can be learnt in a practice but also how to conjugate different practices in a more complex social scope. There is in human beings a tendency for history, for narrating, for sharing stories that represent the individual experiences, in this way are made interpretations that reflect moral commitments established by a society or by that which wants to be a society. This is one of the most powerful ways to produce social unity as well as to look for the unity of every individual.

In this light, Grisez and Shaw [33] point out "when we determine ourselves through commitments we shape our lives, our way of looking at things, we determine the significance of the experience that we will have. In such a way, we really create situations in a moral way, since we give to events that happen in our lives and in the world the only meaning they have for us".

The ideal community is, for MacIntyre, the one that carries out a coherent tradition and that in addition is able to make its position rationally explicit, as much in its interior to those who share the project of the community, as towards the outside, to the rival traditions from which it is distinguished. This happens without excluding or discriminating from the beginning the incorporated achievements of those different traditions from such community. In this sense the tradition to which MacIntyre is referring is that where a healthy realism in education is possible: "Tradition of virtues".

\section{Narrativity in Education}

The previously indicated thing to obtain this element is developed by MacIntyre in his work After Virtue, when affirming the importance of narrative in human life and in the development of people. Both elements are closely tied in the scope of education.

MacIntyre states in his own experiences as a child the importance of narrative in education. For him "telling stories is a key issue for educating in virtues" [13]. In fact, he attributes a decisive role in formation to stories in general and particularly to the Gaelic sagas as transmitters of a distinctive tradition, in many ways in opposition to the dominant tradition of modern societies, shedding light "these narratives supply, adequately or not, the historical memory of societies where finally they were fixed in writing. More than that, they give the moral ground of the contemporary debate in classic societies, the vision of a moral order partially or completely transcended, whose beliefs and concepts were still partially influential, and gives also an illuminating contrast to the present time" [13].

MacIntyre emphasizes the importance and the necessity of narrative and the communication of proper stories of a concrete tradition during the first stages of education. In some way MacIntyre goes to his personal experience. The stories that we heard when we were children allow us to learn what a parent and a child are, and what kind of society we live in, etc. If we deprive children of these narratives, they could not distinguish nor wander a world presented as unknown for us [13].

Narrativity in education is seen as a necessary tool to show the unity of human life in an intelligible way, but also to claim the unity of traditions through which we make contact, or those which constitute our nutritional moral habitat.

Then education is taken as a promise of a novelty and the new beginnings with each person keeping the possibilities of the world that is coming from the past. This also requires from every educator to learn how to organize teaching time. Think about the rhythm of learning as well as the maturity of the students. Make students, when they are able to do so, think about their rhythm of learning. For each student, reaching that goal means learning how to organize their lives, which entails making an election of priorities.

Thus, helping students reflect on goals supposes understanding who we are, when, and where we are going. Then narrative is manifested as an efficient help for the proper goal of education: to be happy [34], insofar as it allows us to discover who and how we are. From the old times human beings have used told stories as an efficient means for moral education; therefore, we consider that this method is still very useful today $[35,36]$.

In a different way Geneviève Patte [37], discloses an slogan that succeeded even among teachers "let them read!", proposing leading students with respect but taking into account that "the child has to be conscious that she is living a decisive time where every book has to be "too good to miss"; books and stories that could play an essential role in the development of her personality, of her affective and intellectual life".

Nonetheless it is true that for students, being only part of one tradition, there is a time when she faces other cultures that, in many cases, would be differing versions of her own tradition $[38,39]$. This is the moment for dialectic and rational discussion, where narrative has its imitation in drama. The importance of dramatic narratives is crucial as an example of attitudes that must be adopted in the situation of conflict among cultures that is brought throughout the dialectic among traditions. For a good solution of this possible conflict, MacIntyre [40] takes 
into account the necessity and fecundity of this phase, foreseeing and nourishing through the help of narrative models of historical character.

With the passage of time narrative has to be applied to one's own life and to autobiography. It happens to be a necessary genre to give unity to one's own life project and to make it intelligible to the eyes of those who surround us, sharing or not the tradition in which we live. To reach this goal we need a narrative of the context in which we located ourselves, otherwise the autobiographical story could not be possible either.

In the end, the ideal story which MacIntyre advocates, as we indicated in the beginning, is the one of a search: that in which each person is committed to the truth. The search for human life is obtained as a whole. Indeed that search becomes total and intelligible because it is able, albeit always in a limited way, to give a coherent explanation of truth as well as of the good that we pursue. As MacIntyre exposes by means of narrative we can discover and give an answer to the great questions that are posed by human beings: who am I and what am I?

Discovering oneself and discovering ourselves. The answer to this question that we considered at the beginning is expressed in a very clear way by MacIntyre $[41,42]$ "people at certain moments of their lives often discover and the crucial word is discovered that their lives have taken a narrative form independently of anything they wanted. And this discovery that in their lives has a narrative form, looking back can rather be understood as a movement in one direction rather than in another. Is not the discovery that the rest of their life is predetermined, but a discovery that there are objective limitations coming from the past in the options that what one can do, and in the meaning of those options. The problem with social constructivism is that it does not recognize the necessary objectivity of social orders".

\section{Conclusions}

According to McIntyre tradition is an essential dimension of personal identity. One way of growing in self-understanding is by expressing in narrative form those contradictions, experiences, states of mind, and moods that connect me to others and help me to discover who and what I am. In this vein, a task of the first importance in the intellectual life is the narrative articulation of one's autobiography, whether of one's past life or of one's most intimate aspirations for the future, in the context of a community of learning. This is the way one becomes effectively the author of one's own life, discovering what connects me to others and discovering who I am.

What we understand about ourselves is the result of a narrative articulation of the events that we have lived.
But we only grasp the true meaning of lived events when we compare what we were with what we could have been. This last idea, the possible, we can know, even if we have not lived it, through fictional stories. With the connection between the historical and the fictional, our personal identity - which is, in the end, a narrative - is finally built up.

Therefore it is no surprise that for many theoreticians, narrative has become a category well-suited to describe those human sciences which involve, in one way or another, discourse and temporality. It is through narrative that one attains an understanding of oneself, gives value to those actions framed by a narrated life, grasps the meaning of history, and discovers one's personal identity.

\section{REFERENCES}

[1] H.-G. Gadamer, "Verdad y Método," Traducido por Ana Agud Aparicio y Rafael de Agapino, Sígueme, 1991.

[2] R. Spaemann, "Ética: Cuestiones Fundamentales," Versión Española y Prólogo, José María Yanguas, Eunsa, 2001.

[3] A. MacIntyre and J. Dunne, "Alasdair MacIntyre on Education: In Dialogue with Joseph Dunne," Journal of Philosophy of Education, Vol. 36, No. 1, 2002, pp. 1-19.

[4] K. C. MacLean, M. Pasupathi and J. L. Pals, "Selves Creating Stories Creating Selves: A Process Model of Self-Development," Personality and Social Psychology Review, Vol. 11, No. 3, 2007, pp. 262-278.

[5] M. J. Chandler and T. Proulx, "Identity and Story: Creating Self in Narrative," Journal of Applied Developmental Psychology, Vol. 28, No. 3, 2007, pp. 277-282.

[6] W. T. Kraus, "The Narrative Negotiation of Identity and Belonging," Narrative Inquiry, Vol. 16, No. 1, 2006, pp. 103-111.

[7] C. Taylor, "Sources of the Self: The Making of the Modern Identity," Cambridge University Press, Cambridge, 1989.

[8] A. MacIntyre, "Three Rival Versions of Moral Enquiry: Encyclopaedia, Genealogy, Tradition," Duckworth and University of Notre Dame, Notre Dame, 1990.

[9] S. Sayers, "Identity and Community," Journal of Social philosophy, Vol. 30, No. 1, 1999, pp. 147-160.

[10] A. Llano, "Presentación," en MacIntyre, A., Tres Versiones Rivales de la ética. Encyclopaedia, Genealogía y Tradición, Traducción de Rogelio Rovira, Rialp, 1992.

[11] M. Papapstephanou, "Education, Subjectivity and Commnity: Towards a Democratic Pedagogical Ideal of Symmetrical Reciprocity," Educational Philosophy and Theory, Vol. 35, No. 4, 2003, pp. 395-406.

[12] P. Verhesschen, “The Poem's Invitation: Ricoeur's Concept of Mimesis and its Consequences for Narrative Educational Research," Journal of Philosophy of Education, Vol. 37, No. 3, 2003, pp. 449-465.

[13] A. MacIntyre, "After Virtue: A Study in Moral Theory," 
Duckworth and University of Notre Dame, Notre Dame, 1981.

[14] B. Hardy, "Towards a Poetics of Fiction: An Approach through Narrative," Novel, No. 2, 1968, pp. 5-14.

[15] P. Kemp, "Mimesis in Educational Hermeneutics," Educational Philosophy and Theory, Vol. 38, No. 2, 2006, pp. 171-184.

[16] L. O. Mink, "History and Fiction as Modes of Comprehension," New Literary History, No. 1, 1970, pp. 541558.

[17] P. Ricoeur, "De l'interprétation, en Du texte à l'action. Essais d'herméneutique II," Seuil, 1986.

[18] P. Ricoeur, "Soi-Même Comme un Autre," Seuil, 1990.

[19] H. Arendt, "La Condición Humana," Introducción de Manuel Cruz; Traducción de Ramón Gil Novales, Paidos, 1993.

[20] H. Arendt, "Hombres en Tiempos de Oscuridad," Traducción Claudia Ferrari, Gedisa, 1992.

[21] K. D. Heyer and A. Fidyk, "Configuring Historical Facts through Historical Fiction: Agency, Art-in-Fact and Imagination as Stepping Stones between Then and Now," Educational Theory, Vol. 57, No. 2, 2007, pp. 141-157.

[22] S. D. Franzosa, "Authoring the Educated Self: Educational Autobiography and Resistance", Educational Theory, Vol. 42, No. 4, 1992, pp. 395-412.

[23] S. Farquhar and P. Fitzsimons, "Introduction. Philosophy of Early Childhood Education," Educational Philosophy and Theory, Vol. 39, No. 3, 2007, pp. 225-228.

[24] P. Ricoeur, "Temps et récit," Seuil, 1983.

[25] I. Olábarri, "New History: A Longue Durée Structure," History and Theory, Vol. 34, No. 1, 1995, pp. 1-29.

[26] K. Hawkey, "Could You Just Tell Us the Story - Pedagogical Approaches to Introducing Narrative in History Classes," Curriculum Inquiry, Vol. 37, No. 3, 2007, pp. 263-277.

[27] G. Steiner, "Presencias Reales, Hay Algo en lo Que Decimos?," Destino, 1991.

[28] S. Rice, "Teaching and Learning through Story and Dialogue," Educational Theory, Vol. 43, No. 1, 1993, pp. 85-97.

[29] J. Russell, "Consciousness in a Community of Inquiry,"
Journal of Moral Education, Vol. 31, No. 2, 2002, pp. 141-153.

[30] J. Dunne, "Arguing for Teaching as a Practice: A Reply to Alasdair MacIntyre," Journal of Philosophy of Education, Vol. 37, No. 2, 2003, pp. 353-369.

[31] K. Wain and K. MacIntyre, "Teaching, Politics and Practice," Journal of Philosophy of Education, Vol. 37, No. 2, 2003, pp. 225-239.

[32] T. McLaughlin, "The Educative Importance of Ethos," British Journal of Educational Studies, Vol. 53, No. 3, 2005, pp. 306-325.

[33] G. Grisez and R. Shaw, "Ser Persona: Curso de ética," Versión Española, Realizada por Manuel Alcázar García, Rialp, 1993.

[34] F. Altarejos, "Dimensión ética de la Educación," Eunsa, 1999.

[35] A. Cain, "Becoming Good: Demonstrating Aristotle's Theory of Moral Development in the Act of Reading," Journal of Moral Education, Vol. 34, No. 2, pp. 171-183.

[36] D. Carr, "On the Contribution of Literature and the Arts to the Educational Cultivation of Moral Virtue, Feeling and Emotion," Journal of Moral Education, Vol. 34, No. 2, 2005, pp. 137-151.

[37] G. Patte, "Laissez-Les Lire," Enfance Heureuse, 1987.

[38] J. Cohen, "Deliberation, Tradition, and the Problem of Incommensurability: Philosophical Reflections on Curriculum Decision Making," Educational Theory, Vol. 49, No. 1, 1999, pp. 71-89.

[39] D. Resnick, "What Could Be Better Than This? - Conflicting Visions of the Good Life in Traditional Education," Journal of Philosophy of Education, Vol. 40, No. 3, 2006, pp. 391-403.

[40] A. MacIntyre, "Are Philosophical Problems Insoluble? the Relevance of System and History," Philosophical Imagination and Culture Memory: Appropriating Historical Traditions, Duke University Press, Durham, 1993, pp. 65-82.

[41] A. MacIntyre, "Interview with Alasdair MacIntyre," Kinesis, Vol. 20, No. 2, 1994, pp. 34-47.

[42] D. P. Mc Adams, "The Problem of Narrative Coherence," Journal of Constructivist Psychology, Vol. 19, No. 2, 2006, pp. 109-125. 